\title{
CARACTERÍSTICAS Y EFECTOS DE LA INNOVACIÓN EN EMPRESAS DE BOLIVIA: UNA APLICACIÓN DEL MODELO CDM
}

\section{Carlos Foronda Rojas}

\section{RESUMEN}

El estudio realiza una adecuación para Bolivia del modelo desarrollado por Crepon, Duguet, y Mairesse (CDM) en 1998, el cual permite estimar el impacto y los resultados de los esfuerzos en actividades de innovación de las empresas sobre su productividad. Para el estudio se empleó la primera encuesta de innovación realizada en Bolivia a empresas privadas. La metodología y la base de datos empleadas permiten la comparabilidad de los resultados con diferentes países de Latinoamérica. Los resultados muestran que, en Bolivia, la propiedad de una patente, las fuentes de información de mercado y las tecnológicas son determinantes del nivel de inversión en innovación. Los esfuerzos de inversión en innovación tecnológica por empleado permiten incrementar la probabilidad de obtener innovación tecnológica en las empresas de manufactura y servicios. Adicionalmente, los resultados muestran la baja conexión que caracteriza al sistema nacional de innovación. A su vez, la productividad laboral de las empresas se incrementa cuando éstas introducen innovación tecnológica, aunque esta última no es significativa. Finalmente, los resultados muestran la importancia de continuar estudiando la innovación en producto y en proceso por separado para demostrar su relación positiva con la productividad laboral.

Palabras Clave: Innovación, Encuesta de Innovación, Productividad, Políticas de Innovación.

DOI: $10.23881 /$ idupbo.018.2-4e 